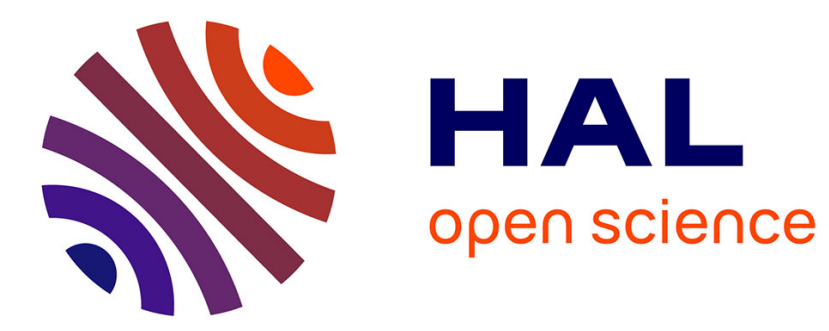

\title{
Does R\&D cooperation facilitate price collusion? An experiment
}

\author{
Sigrid Suetens
}

\section{To cite this version:}

Sigrid Suetens. Does R\&D cooperation facilitate price collusion? An experiment. Journal of Economic Behavior and Organization, 2008, 66 (3-4), pp.822. 10.1016/j.jebo.2007.01.002 . hal-00589720

\section{HAL Id: hal-00589720 https://hal.science/hal-00589720}

Submitted on 1 May 2011

HAL is a multi-disciplinary open access archive for the deposit and dissemination of scientific research documents, whether they are published or not. The documents may come from teaching and research institutions in France or abroad, or from public or private research centers.
L'archive ouverte pluridisciplinaire HAL, est destinée au dépôt et à la diffusion de documents scientifiques de niveau recherche, publiés ou non, émanant des établissements d'enseignement et de recherche français ou étrangers, des laboratoires publics ou privés. 


\section{Accepted Manuscript}

Title: Does R\&D cooperation facilitate price collusion? An experiment

Author: Sigrid Suetens

PII:

S0167-2681(07)00036-4

DOI: doi:10.1016/j.jebo.2007.01.002

Reference: JEBO 2077

To appear in:

Journal

of Economic

Behavior

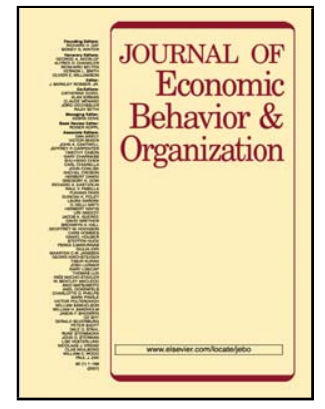

Received date:

14-10-2005

Revised date:

29-1-2007

Accepted date:

29-1-2007

Please cite this article as: Suetens S., Does R\&D cooperation facilitate price collusion? An experiment, Journal of Economic Behavior and Organization (2007), doi:10.1016/j.jebo.2007.01.002

This is a PDF file of an unedited manuscript that has been accepted for publication. As a service to our customers we are providing this early version of the manuscript. The manuscript will undergo copyediting, typesetting, and review of the resulting proof before it is published in its final form. Please note that during the production process errors may be discovered which could affect the content, and all legal disclaimers that apply to the journal pertain. 
Elsevier Editorial System(tm) for Journal of Economic Behavior \& Organization

Manuscript Draft

Manuscript Number: JEBO-D-05-00058R3

Title: Does R\&D cooperation facilitate price collusion? An experiment

Article Type: Full Length Article

Keywords: R\&D cooperation; price collusion; duopoly; experiment

Corresponding Author: Dr. Sigrid Suetens,

Corresponding Author's Institution: University of Antwerp

First Author: Sigrid Suetens

Order of Authors: Sigrid Suetens

Abstract: We examine in a laboratory experiment whether R\&D cooperation facilitates tacit price collusion. For two scenarios of technological spillovers, a baseline treatment without binding contract possibilities and a contract treatment where it is possible to credibly commit to an R\&D contract, are run. We find that the degree of price collusion in the contract treatments is significantly higher in periods where R\&D contracts are made than in periods without contracts, and than in the baseline treatments. 


\title{
Does R\&D cooperation facilitate price collusion? An experiment.
}

\author{
Sigrid Suetens
}

April 2006

\author{
Affiliation \\ University of Antwerp \\ Department of Economics \\ Prinsstraat 13 \\ B-2000 Antwerpen \\ phone +32 32204038 \\ fax +3232204585 \\ e-mail: sigrid.suetens@ua.ac.be
}

\section{Acknowledgments}

The experiment discussed in this paper was run during my Marie Curie stay at CentER (Tilburg University) from February to June 2003. I thank Jan Potters, Dudley Cooke, participants at the ESA conference in Pittsburgh (2003), the EARIE 2004 conference in Berlin and those at seminars at CentER (Tilburg University), the University of Antwerp and ENCORE (University of Amsterdam), two anonymous referees and an Associate Editor for providing useful comments. I further thank Daimler Chrysler Services for sponsoring the Young Economist Award I received at EARIE 2004, and Tilburg University and the Research Foundation Flanders (FWO) for providing financial support.

\section{Introduction}

To protect consumers, public authorities forbid firms to engage in price collusion or other agreements that restrict output ${ }^{1}$. The formation of research

\footnotetext{
${ }^{1}$ See, for example, the Sherman Act in the US and Articles 81-86 of the EC Treaty.
} 
joint ventures or other cooperative $\mathrm{R} \& \mathrm{D}$ agreements is not forbidden, however, but encouraged by governments because of possible welfare-enhancing effects $^{2}$. A theoretical underpinning for the encouragement of R\&D cooperation is provided in the models of d'Aspremont and Jacquemin (1988) and Kamien et al. (1992) (see also Suzumura 1992, Brod and Shivakumar 1997, Petit and Tolwinski 1999, Hinloopen 2003). These models find that R\&D cooperation enhances social welfare if pre-cooperative or at least postcooperative technological spillovers amongst the cooperating firms are sufficiently high, given that Cournot or Bertrand competition prevails in the product market. It is typically assumed that firms behave according to the subgame perfect Nash (SPN) equilibrium in the product market, irrespective of whether they cooperate in the R\&D stage.

An intuitively appealing and empirically relevant question is whether cooperation in $\mathrm{R} \& \mathrm{D}$ may translate into tacit collusion in the product market. If such a relation exists, it is unclear, even for sufficiently high spillovers, whether R\&D cooperation is preferred on social welfare grounds. Moreover, econometric estimations of the $R \& D$ models based on field data would give seriously biased results.

Martin (1995), van Wegberg (1995), Cabral (2000) and Lambertini et al. (2002) provide a theoretical framework to investigate whether R\&D cooperation facilitates cooperation in the product market. A general finding is that R\&D cooperation makes it more likely for tacit collusion to be sustained in the product market. Vonortas (2000) provides empirical support by studying the relationships between firms in research joint ventures that are formed under the National Cooperative Research Act in the US. The author suggests that the scope for collusive play in the product market is enlarged by the combination of multi-R\&D-project and multimarket contact.

In this paper we investigate whether cooperation in cost-reducing R\&D facilitates product market collusion in an experiment. A laboratory experiment allows a ceteris paribus investigation of the relation between $R \& D$ cooperation and product market collusion. It avoids endogeneity and measurement problems that most likely arise in econometric analyses based on field data.

In the experiment subjects repeatedly play a game inspired by the static two-stage models of d'Aspremont and Jacquemin (1988) and Kamien et al. (1992). Taking into account the remark of Holt (1995) that the Cournot model is more mechanical because it simulates price determination mechanics (see also Tirole 1995, pages 223-224), Bertrand competition is implemented

\footnotetext{
${ }^{2}$ See the National Cooperative Research and Production Act in the US and Exemption 81(3) of the EC Treaty.
} 
in the product market.

Treatments where subjects have the possibility to make binding R\&D agreements are compared with baseline treatments without this possibility. No binding commitments are allowed in the product market. Given the importance of the level of technological spillovers in the theoretical and empirical R\&D literature (empirical studies are, e.g., Cassiman and Veugelers 2002, Kaiser 2002, Hernán et al. 2003, Belderbos et al. 2004), the contract and baseline treatments are run for a scenario without spillovers and for a scenario with perfect spillovers.

The experimental evidence supports the hypothesis that R\&D cooperation facilitates price collusion: the degree of price collusion is significantly higher in rounds where R\&D agreements are made than in rounds without $\mathrm{R} \& \mathrm{D}$ agreements and than in the baseline treatments.

Related laboratory research shows that collusion in the product market is also facilitated by the possibility of announcing or signaling prices (Holt and Davis 1990, Cason 1995, Harstad et al. 1998) and, under certain conditions, by the ability to share information on demand or cost conditions (Cason 1994, Cason and Mason 1999). Moreover, collusion is more likely in repeated games (Davis and Holt 1993, Keser 2000) and when the number of sellers is low (Holt 1995, Huck et al. 2004). Whether engaging in binding R\&D contracts facilitates price collusion has not been examined in an experiment before.

Examples of other related laboratory $R \& D$ experiments are Isaac and Reynolds (1992) and Jullien and Ruffieux (2001). Both are dynamic experiments and focus on the evolution of market prices in a setting where stochastic non-cooperative R\&D decisions can be made. Neither of the experiments allows participants to commit to binding R\&D contracts. In Suetens (2005a) participants can commit to R\&D contracts, but do not make product market decisions.

The remainder of the paper is organized as follows. In section 2, an outline of the theoretical model is given. Section 3 provides the experimental design and procedure that has been followed. The experimental results are in section 4. Data from an additional random-matching treatment are discussed in section 5. Section 6 concludes.

\section{Theoretical predictions}

The model that serves as a benchmark for the experiment is a modified version of the AJ and KMZ models (d'Aspremont and Jacquemin 1988, Kamien et al. 1992). Two firms compete over prices and sell differentiated products. 
The firms face the following linear demand curve in period $t$, with $i, j=1,2$ and $i \neq j^{3}$ :

$$
q_{i t}\left(p_{i t}, p_{i t}\right)=\frac{a}{b+c}-\frac{b p_{i t}-c p_{j t}}{b^{2}-c^{2}} .
$$

Each firm decides on R\&D investment in period 1. It is assumed that investing in $\mathrm{R} \& \mathrm{D}$ reduces unit production costs and gives rise to a cost in period 1 and in all subsequent periods. After the R\&D decision, firms make a fixed number $(m)$ of subsequent price decisions ${ }^{4}$.

This modification to the original KMZ and AJ models is motivated by reasons of experimental design. In this way, subjects can assign changes in their profits to changes in price decisions in a straightforward way and can learn to make price decisions, given their RED decisions. Besides, the assumption that $R \& D$ decisions have a longer-term character than price decisions seems plausible.

It is further assumed that technological spillovers may arise that reduce the unit cost of the competitor. Replacing quantities by the direct demand curves and assuming that $\mathrm{R} \& \mathrm{D}$ has decreasing returns yields the following profit function of firm $i$ in period $t$ :

$$
\pi_{i t}=\left(\frac{a}{b+c}-\frac{b p_{i t}-c p_{j t}}{b^{2}-c^{2}}\right)\left(p_{i t}-\left[\alpha-\left(x_{i 1}+\beta x_{j 1}\right)\right]\right)-\delta \frac{x_{i 1}^{2}}{2},
$$

where $p_{i t}$ is the price of products sold by firm $i$ in period $t$ and $x_{i 1}$ the R\&D investment of firm $i$ in period 1. $\beta$ represents the spillover parameter that lies between 0 and 1, $\alpha$ stands for unit production cost if neither firm invests in $\mathrm{R} \& \mathrm{D}$, and the last term is the $\mathrm{R} \& \mathrm{D}$ cost function.

As suggested by Amir (2000), a steeper R\&D cost function is used in order to obtain decreasing returns to effective $\mathrm{R} \& \mathrm{D}$ (that is, $x_{i 1}+\beta x_{j 1}$ ). In particular, $\delta=\gamma(1+\beta)$ in the R\&D cost function, where $\gamma$ is the original AJ cost parameter. By using this alternative cost function, equilibrium R\&D predictions are equivalent with KMZ, but the decision variables in the $\mathrm{R} \& \mathrm{D}$ stage are unit cost reductions as in $\mathrm{AJ}^{5}$.

The game is solved by backward induction. Since firms are not allowed to make binding agreements in the product market, the solution concept of each price-setting stage of the game is the SPN equilibrium. Thus, the profit of firm $i$ is maximized with respect to its price in each period $t$ starting with the final period $m$. This yields the following equilibrium solution for the

\footnotetext{
${ }^{3}$ The inverse demand curve is $p_{i t}\left(q_{i t}, q_{j t}\right)=a-b q_{i t}-c q_{j t}$.

${ }^{4}$ In the experiment $m=5$.

${ }^{5}$ Amir shows this for the case of quantity competition with homogeneous products, but the same goes for the modified game with price competition and differentiated products.
} 
price of firm $i$ in period $t$, in terms of the R\&D decisions made by both firms in the first period:

$$
p_{i t}^{\mathrm{SPN}}=\frac{(2 b+c)[a(b-c)+\alpha b]-b\left[(2 b+\beta c) x_{i 1}+(2 b \beta+c) x_{j 1}\right]}{4 b^{2}-c^{2}} .
$$

If firms cannot make binding agreements with respect to their $R \& D$ investment in the $R \& D$ stage, this stage is also played non-cooperatively. The solution concept is again the SPN equilibrium. Substituting equilibrium prices (eq. 3) into the profit function (eq. 2) and maximizing the profit function in the R\&D stage yields the following symmetric $R \& D$ equilibrium in period 1, where superscripts in capitals (subscripts in lower-case letters) refer to competition in prices $(\mathrm{R} \& \mathrm{D})^{6}$ :

$$
x_{\mathrm{spn}}^{\mathrm{SPN}}=\frac{2 b(a-\alpha)\left(2 b^{2}-b \beta c-c^{2}\right)}{(1+\beta)\left[\gamma(b+c)(2 b+c)(2 b-c)^{2}-2 b\left(2 b^{2}-b \beta c-c^{2}\right)\right]} .
$$

If firms are allowed to make binding $R \& D$ agreements and can reliably commit to a cooperative R\&D level, joint profit is maximized with respect to $\mathrm{R} \& \mathrm{D}$. This yields the following (symmetric) cooperative outcome for $i=1,2$ in period $1^{7}$ :

$$
x_{\mathrm{jpm}}^{\mathrm{SPN}}=\frac{2 b(a-\alpha)(b-c)}{\gamma(b+c)(2 b-c)^{2}-2 b(1+\beta)(b-c)} .
$$

The cooperative R\&D level is larger (smaller) than the SPN R\&D level if actions in the $R \& D$ stage are strategic complements (substitutes), i.e. if $\beta>(<) \frac{b c}{2 b^{2}-c^{2}}$. Profits that correspond to R\&D cooperation are higher than profits under R\&D competition if $\beta \neq \frac{b c}{2 b^{2}-c^{2}}$.

Finally, consider the benchmark case of price collusion. If firms collude in prices in period $t$, the following price can be derived for firm $i$ in terms of own R\&D and R\&D of the other firm:

$$
p_{i t}^{\mathrm{JPM}}=\frac{a+\alpha-\left(x_{i 1}+\beta x_{j 1}\right)}{2} .
$$

Given the R\&D decisions, the collusive price is higher than the SPN price for all parameter values. If firms expect to collude in the $m$ price-setting

\footnotetext{
${ }^{6}$ It is assumed that the second-order conditions and the stability conditions suggested by Henriques (1990) are met.

${ }^{7}$ It is again assumed that the second-order condition is met. We also assume that the cooperative R\&D level is unique and symmetric (see Salant and Shaffer 1998).
} 


\begin{tabular}{|c|c|c|c|c|c|c|c|c|}
\hline & $x_{\mathrm{spn}}$ & $x_{\mathrm{jpm}}$ & $p_{\text {spn }}$ & $p_{\mathrm{jpm}}$ & $\pi_{\mathrm{spn}}$ & $\pi_{\mathrm{jpm}}$ & $W_{\text {spn }}$ & $W_{\mathrm{jpm}}$ \\
\hline \multicolumn{9}{|c|}{ SPN behavior in price-setting stage } \\
\hline$\beta=0$ & 17.4 & 9.5 & 85.3 & 91.2 & 862.6 & 891.0 & 4779.6 & 4614.0 \\
\hline$\beta=1$ & 4.8 & 10.0 & 91.2 & 83.3 & 913.8 & 936.8 & 4657.5 & 5003.6 \\
\hline \multicolumn{9}{|c|}{ Collusion in price-setting stage } \\
\hline$\beta=0$ & 28.0 & 13.0 & 133.5 & 141.0 & 1112.1 & 1214.2 & 3713.6 & 3723.4 \\
\hline$\beta=1$ & 6.5 & 13.9 & 141.0 & 133.6 & 1254.6 & 1300.7 & 3804.2 & 4087.6 \\
\hline
\end{tabular}

Table 1: Theoretical benchmarks

stages, profits in the $R \& D$ stage are formulated in terms of the collusive prices. This yields other predictions for the SPN and cooperative R\&D levels in period 1 . These are respectively:

$$
\begin{gathered}
x_{\mathrm{spn}}^{\mathrm{JPM}}=\frac{(a-\alpha)[2 b-c(1+\beta)]}{(1+\beta)[4 \gamma(b-c)(b+c)-2 b+c(1+\beta)]} \quad \text { and } \\
x_{\mathrm{jpm}}^{\mathrm{JPM}}=\frac{(a-\alpha)}{2 \gamma(b+c)-(1+\beta)} .
\end{gathered}
$$

The theoretical benchmarks that correspond to the parameters chosen in the experiment are given in table $1^{8}$. With respect to the choice of parameter values, we have tried to ensure that the sensitivity of profit to an increase in R\&D is sufficiently high, but it is inherent to the model that the sensitivity of profit to a price change is higher than to a change in R\&D. Parameter values used in the experiment are $a=245, \alpha=50, b=5, c=3.35$ and $\gamma=0.96$. Turning from individual to joint profit maximizing R\&D yields a profit increase of 3 to $9 \%$, depending on price-setting behavior and the level of spillovers, while turning from the individual to the joint profit maximizing price yields a profit increase of 29 to $39 \%$, depending on R\&D decisions and $\beta$.

In the scenario with $\beta=0, \mathrm{R} \& \mathrm{D}$ cooperation yields a reduction in welfare, given that firms compete in prices in the second stage. On the contrary, with $\beta=1$, welfare is increased under $\mathrm{R} \& \mathrm{D}$ cooperation. If firms collude in prices, welfare is always lower compared to when they compete.

Theory predicts prices to be symmetric and at the SPN level in each period $t$, irrespective of whether binding agreements can be made in the $R \& D$ stage. It also predicts that $R \& D$ is at the SPN level if no binding $R \& D$ agreements can be made and at the cooperative level if $R \& D$ agreements can be and are made. In the experiment the modified game is repeated

\footnotetext{
${ }^{8}$ The parameters satisfy stability conditions (Henriques) and the conditions for R\&D solutions to be symmetric (Salant and Shaffer).
} 


\begin{tabular}{ccc}
\hline & BASE & CON \\
\hline \hline$\beta=0$ & $30(15)$ & $32(16)$ \\
$\beta=1$ & $22(11)$ & $30(15)$ \\
\hline
\end{tabular}

Table 2: Treatments and number of subjects (duopolies)

7 times so as to represent repeated interaction between firms in oligopoly markets. Thus, each subject makes $7 \mathrm{R} \& \mathrm{D}$ decisions and 35 price decisions in total (excluding the trial rounds). It is clear from following the backward induction rule that finitely repeating the game does not change the theoretical predictions.

\section{Experimental design and procedure}

The experiment was run in CentERlab at Tilburg University and consisted of six computerized sessions with a total number of 114 recruited students. The software $z$-Tree developed by Fischbacher (1999) was used. Students were undergraduates in economics, law or social sciences and had participated before in other types of experiments. Each session lasted for two hours and earnings were between 11.5 and 30.5 EUR. Before the experiment started, instructions (see appendix $\mathrm{A}^{9}$ ) were handed out and the students had the opportunity to ask questions. During the trial rounds, instructions were clarified aloud.

The experiment consisted of four treatments: a baseline treatment without contract possibilities (BASE) and a treatment with contract possibilities $(\mathrm{CON})$, both for a scenario without technological spillovers $(\beta=0)$ and with full spillovers $(\beta=1)$. The number of participants and duopolies in each treatment is given in table 2 .

The instructions made clear that the subjects represented a seller-producer of an unspecified product in a market with two sellers of a similar, but not identical product, and that demand of consumers was simulated by the computer. The duopolies were fixed during the experiment and subjects had no knowledge of the identity of their counterpart. Subjects were told that (the simulated) consumers buy more (less) of their own product and less (more) of the product of their counterpart, the lower (higher) the prices of their own product. In all treatments the demand curve was $q_{i}\left(p_{i}, p_{j}\right) \approx 29.34-0.36 p_{i}+$ $0.24 p_{j}$ based on an inverse demand curve of $p_{i}\left(q_{i}, q_{j}\right)=245-5 q_{i}-3.35 q_{j}$. Subjects knew that their counterpart was subject to the same conditions.

\footnotetext{
${ }^{9}$ All appendices are available on the JEBO website.
} 
The subjects were asked to make investment $(\mathrm{R} \& \mathrm{D})$ and price decisions during 35 rounds, preceded by five practice rounds aimed at getting acquainted with the computer program. The decisions made in the practice rounds were ignored when calculating final remunerations. Investment was constrained to be between 0.0 and 50.0 and the price between 0.0 and 245.0. Investment decisions were made every five rounds and remained at the same level during five subsequent rounds. Price decisions were made in all 35 rounds.

It was also explained to the subjects that investment reduced unit production costs by an equal amount (and unit production costs of the other producer in case of $\beta=1$ ). However, investing also incurred a cost of half of the square of the amount (the square of the amount in case of $\beta=1)^{10}$. A profit calculator was always available where own profit and profit of the other duopolist could be automatically calculated if fictive values of investment and price decisions were filled in. Decisions made in the previous round were shown on the screen.

In the investment stage of the contract treatments, an additional frame was shown on the screen that enabled subjects to send a contract proposal to their counterpart. In order to replicate the theoretical scenario of R\&D cooperation as closely as possible and not to complicate further the possible interactions, contracts were imposed to be symmetric and binding. It was stressed that the sender of a proposal was committed to his proposal once the counterpart accepted it, even if other proposals were made by either of them. All contract proposals were numbered, and if a contract was accepted, the number of the accepted contract was shown on the screen. The amount of contract proposals per round was not limited as long as no contract was accepted in that round and as long as one of the two players had not entered the $R \& D$ decision in that round. The implemented contracting device has been shown to be effective in eliciting $R \& D$ cooperation in an experiment without a pricing stage in cases with and without full technological spillovers (see Suetens 2005a).

When all investment decisions were entered, subjects were informed about their own and their counterpart's decision and the following stage started. When all price decisions were entered, they were informed about their own and their counterpart's price decisions and the level of profit in that round. Profit in experimental units was generated following equation (2). Remunerations in EUR were calculated by dividing the sum of profits in experimental units over the 35 rounds by 1500, and subjects were informed about this

\footnotetext{
${ }^{10}$ The parameter value of $\gamma$ has been set to 0.96 , such that $\delta \approx 1$ with $\beta=0$ and $\delta \approx 2$ with $\beta=1$.
} 


\begin{tabular}{ccrcc}
\hline & \multicolumn{2}{c}{ price } & \multicolumn{2}{c}{ R\&D } \\
& BASE & \multicolumn{1}{c}{ CON } & BASE & CON \\
\hline \hline$\beta=0$ & $94.3(24.0)$ & $103.2(24.2)$ & $19.9(5.3)$ & $20.1(7.6)$ \\
$\beta=1$ & $93.5(19.9)$ & $93.5(24.2)$ & $10.6(6.4)$ & $17.4(7.3)$ \\
\hline
\end{tabular}

Table 3: Average prices and R\&D decisions (standard deviations)

exchange rate.

\section{Experimental results}

Table 3 provides a brief summary of average prices and R\&D decisions and their standard deviations in the four treatments. With $\beta=0$ the average price in $\mathrm{CON}$ is higher than in BASE, and average $R \& D$ decisions are not very different between BASE and CON. With $\beta=1$ the average price is the same in BASE and CON, and the average R\&D decision in CON is higher than in BASE.

A feature of the multistage game is that benchmark prices are defined in terms of REDD decisions (see equations 3 and 6). This implies that if experimental $R \& D$ decisions change every five rounds, benchmark prices also change. Likewise, benchmark R\&D decisions also depend on subjects' expectations on prices. In what follows in this section, we take these considerations into account. In section 4.1 we discuss the degree of price collusion, and in section 4.2 the $R \& D$ decisions ${ }^{11}$. In all reported statistics, each duopoly is taken as an independent observation.

\subsection{Degree of price collusion}

The main question we are interested in is whether R\&D cooperation facilitates price collusion. In other words, we want to examine whether prices in CON deviate more from the SPN price level toward the collusive price than in BASE. We measure the degree of price collusion of each duopoly in round $t$ as follows:

$$
P_{t}=\frac{\bar{p}_{t}-\bar{p}_{t}^{\mathrm{SPN}}}{\bar{p}_{t}^{\mathrm{JPM}}-\bar{p}_{t}^{\mathrm{SPN}}}
$$

where for each duopoly, $\bar{p}_{t}$ is the average experimental price in round $t$ and $\bar{p}_{t}^{\mathrm{K}}$ with $\mathrm{K}=\mathrm{SPN}$, JPM is calculated on the basis of the experimental R\&D

\footnotetext{
${ }^{11}$ The individual data are available from the author on request or on www.ua.ac.be/sigrid.suetens.
} 
decisions according to equations 3 and 6 . In this way, price benchmarks are defined in terms of the actually observed R\&D decisions. If $P_{t}=0(1)$ the average price of the duopoly in round $t$ is at the SPN (JPM) level, given the $\mathrm{R} \& \mathrm{D}$ decisions made in that round. If $0<P_{t}<1$ the average price of the duopoly in round $t$ is between the SPN and the JPM level, given the R\&D decisions made in that round.

The evolution of the average degree of price collusion in BASE and CON is given in figure $1(\mathrm{a})^{12}$. The figure shows that the degree of price collusion is on average higher in CON than in BASE for both spillover scenarios. Figure 1(b) splits up the average degree of price collusion within CON into an average based on rounds where $R \& D$ contracts were actually made (CON1) and an average based on rounds without $R \& D$ contracts $(\mathrm{CON} 0)^{13}$. More price collusion is observed in rounds with $R \& D$ contracts than in rounds without contracts, for both $\beta=0$ and $\beta=1$.

Another observation from figure 1 is that the average degree of price collusion gradually increases during the experiment and falls in the last round of the experiment due to a well-known end effect. This fall is most pronounced in CON1 and suggests that at least part of the price collusion is strategic. The figure also has a cyclical pattern. In the first round of each five-rounds cycle, there is a jump in price collusion that typically tends to be offset towards the end of the cycle. These observations correspond closely to behavior in earlier experiments on finitely repeated duopoly supergames (see, e.g., Selten and Stoecker 1986).

Means and standard deviations of the degree of price collusion are reported in table $4^{14}$. The different columns in the table refer to different subsets of rounds. $\bar{P}_{1-35}$ is based on all observations in the experiment. $\bar{P}_{26-35}$ is based on the last ten rounds, so as to focus on decisions when subjects have gathered experience in the game. $\bar{P}_{1 s t}$ and $\bar{P}_{5 t h}$ are based on the first, respectively last rounds of each set of five subsequent rounds with a constant $\mathrm{R} \& \mathrm{D}$ decision.

Table 4 shows that the average degree of price collusion is similar in treatments with $\beta=0$ and $\beta=1^{15}$. A relatively high level of price collusion is

\footnotetext{
${ }^{12}$ In 14 out of $1995\left(57^{*} 35\right)$ cases, prices were chosen that yielded a negative production quantity. These observations were left out of all descriptives tables and data analyses. This did not affect the conclusions.

${ }^{13}$ The calculation of averages in rounds with $\mathrm{R} \& \mathrm{D}$ contracts $(\mathrm{CON} 1)$ is based on all rounds of each set of five subsequent rounds where an $R \& D$ contract has been committed to, and thus not only on the first.

${ }^{14}$ Reported standard deviations only give an indication of cross-sectional heterogeneity and not of heterogeneity in time.

${ }^{15}$ Mann-Whitney-U tests confirm that there are no significant differences in degree of price collusion between $\beta=0$ and $\beta=1$ for the BASE and CON.
} 


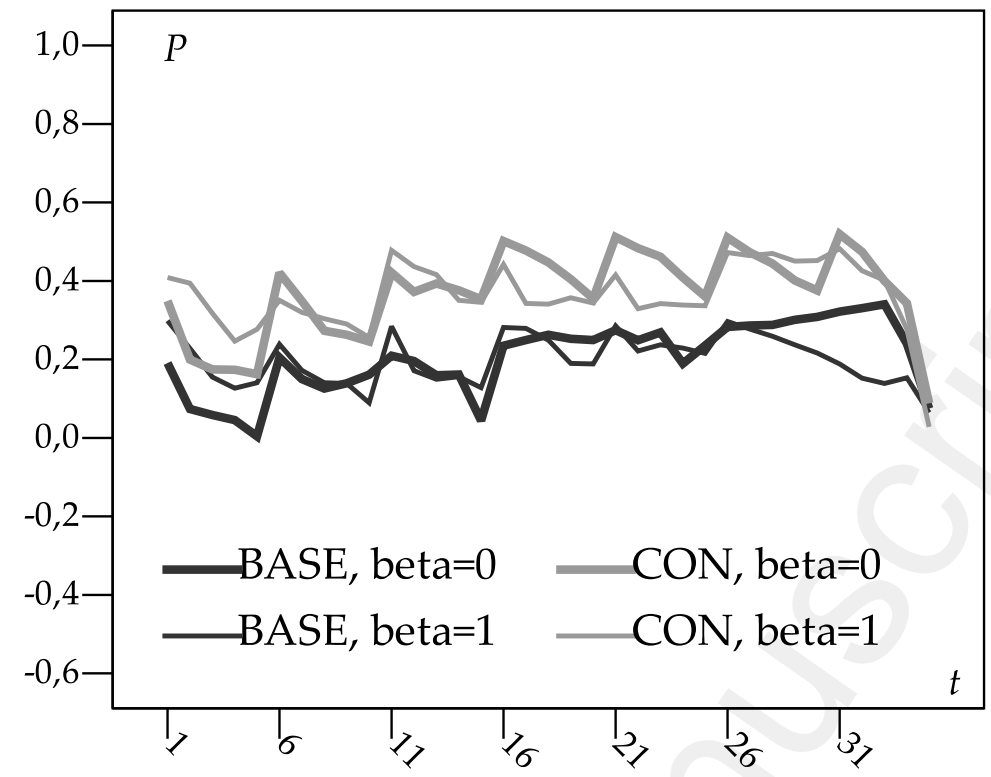

(a) baseline and contract treatments

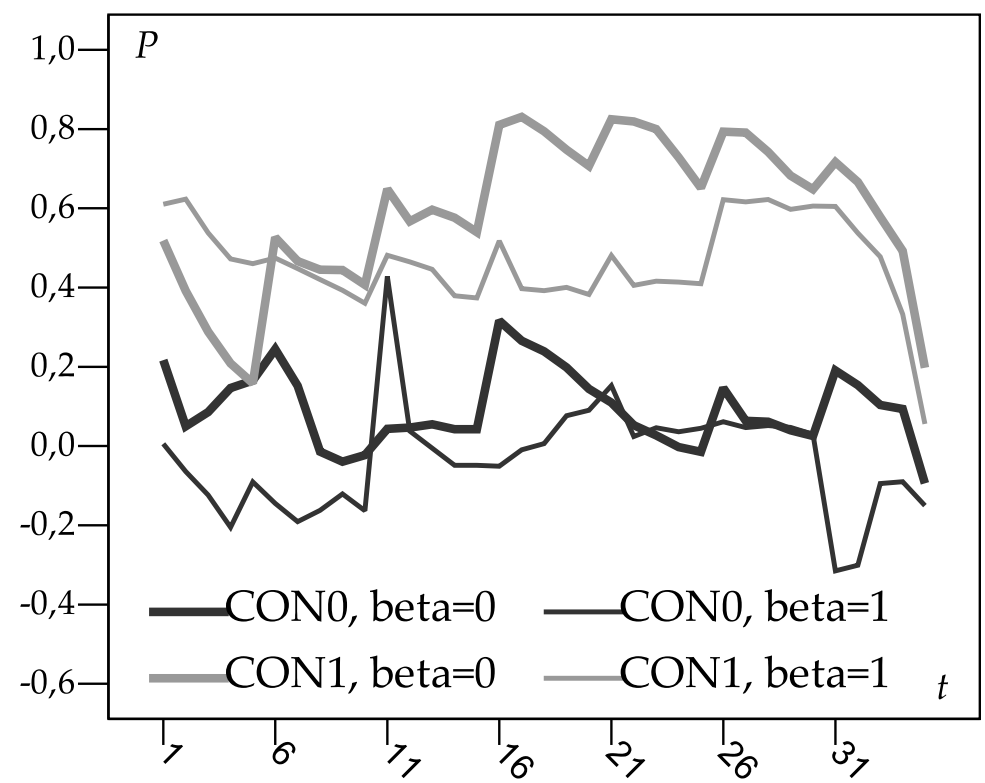

(b) within contract treatments

Figure 1: Evolution of average degree of price collusion

observed in the contract treatments when $R \& D$ contracts were made (CON1). Without contracts (CON0), prices are close to the Nash level. In BASE, prices are slightly above the Nash level. 


\begin{tabular}{lcccc}
\hline Treatment & $\bar{P}_{1-35}$ & $\bar{P}_{26-35}$ & $\bar{P}_{1 s t}$ & $\bar{P}_{5 t h}$ \\
\hline \hline$\beta=0$ & & & & \\
BASE & $0.21(0.33)$ & $0.28(0.41)$ & $0.23(0.32)$ & $0.17(0.32)$ \\
CON0 & $0.12(0.19)$ & $0.06(0.14)$ & $0.21(0.25)$ & $0.08(0.24)$ \\
CON1 & $0.49(0.33)$ & $0.56(0.37)$ & $0.61(0.32)$ & $0.36(0.39)$ \\
\hline$\beta=1$ & & & & \\
BASE & $0.20(0.30)$ & $0.20(0.31)$ & $0.26(0.29)$ & $0.16(0.30)$ \\
CON0 & $-0.03(0.13)$ & $-0.03(0.18)$ & $0.02(0.20)$ & $-0.03(0.12)$ \\
CON1 & $0.41(0.29)$ & $0.43(0.31)$ & $0.51(0.30)$ & $0.31(0.32)$ \\
\hline
\end{tabular}

Table 4: Average degrees of price collusion

\begin{tabular}{lcccc}
\hline rounds & $1-35$ & $26-35$ & 1 st & 5 th \\
\hline \hline between BASE and CONO & & \\
2-tailed sig. & $0.100^{a}$ & $0.140^{a}$ & $0.245^{a}$ & $0.041^{a}$ \\
$\mathrm{~N}$ & 49 & 40 & 49 & 49 \\
between BASE and CON1 & & \\
2-tailed sig. & $0.004^{b}$ & $0.012^{b}$ & $0.001^{b}$ & $0.045^{b}$ \\
$\mathrm{~N}$ & 54 & 52 & 54 & 54 \\
\hline${ }^{a} H_{1}: \bar{P}_{\mathrm{BASE}} \neq \bar{P}_{\mathrm{CON} .} ;{ }^{b} H_{1}: \bar{P}_{\mathrm{CON} .} \neq \bar{P}_{\mathrm{BASE}}$ \\
\hline
\end{tabular}

Table 5: Contract treatment effects on degree of price collusion

Table 5 contains p-values of two-tailed Mann-Whitney-U tests of differences between BASE and CON0 and between BASE and CON1. The underlying numbers of independent observations are also reported ${ }^{16}$. Data from $\beta=0$ and $\beta=1$ are pooled because the degree of price collusion does not significantly differ.

The tests provide strong evidence that the degree of price collusion in CON1 is higher than in BASE. This is also the case in the last ten rounds, where subjects had gained experience ${ }^{17}$. Successful RED cooperation thus facilitates price collusion.

Table 5 further shows that overall there is no significant difference in the degree of price collusion between BASE and CON0. This also goes for the

\footnotetext{
${ }^{16}$ The total number of duopolies that underlie the test results are smaller than the total number of participating duopolies (see table 2) because some duopolies never committed to an R\&D contract and some always did so.

${ }^{17}$ Due to a smaller number of observations, the evidence weakens somewhat when considering $\beta=0$ and $\beta=1$ separately, but the same picture emerges. Only in the final rounds of five-rounds cycles are one-tailed tests combined with a p-value of $10 \%$ needed to draw the same conclusion.
} 


\begin{tabular}{lcccc}
\hline rounds & $1-35$ & $26-35$ & 1 st & 5 th \\
\hline \hline 2-tailed sig. & 0.000 & 0.008 & 0.000 & 0.000 \\
$\mathrm{~N}$ & 20 & 9 & 20 & 20 \\
\hline$H_{1}: \bar{P}_{\mathrm{CON} 1} \not \bar{P}_{\mathrm{CON} 0}$ & & & \\
\hline
\end{tabular}

Table 6: Within contract treatment effects on degree of price collusion

final ten rounds and the first rounds of the five-rounds cycles. In the fifth rounds of the five-rounds cycles, however, the degree of price collusion is significantly lower in CON0 than in BASE. This may indicate that subjects punish one another for not having reached a satisfactory $R \& D$ agreement by lowering their prices below a level that would normally have been reached without contract possibilities. This behavior is in line with the experimental findings discussed in Fehr and Rockenbach (2003) and coincides with the within-treatment test results that are discussed below.

Table 6 contains Wilcoxon signed-ranks test statistics for comparisons within the contract treatment (i.e. between CON0 and CON1). The tests are based on duopolies that switched between committing and not committing to an $R \& D$ contract in the related subset of rounds. Decisions of duopolies that either never or always signed a contract in that subset of rounds necessarily drop out of the within-analysis. This explains the reduction in the number of observations in the table $(\mathrm{N})$ compared to the between-analyses.

As table 6 shows, the difference in degree of price collusion between rounds with and without R\&D contracts is highly significant ${ }^{18}$.

Summarizing, on the basis of between- and within-tests we find strong statistical evidence in favor of the hypothesis that successful R\&D cooperation facilitates price collusion. The degree of price collusion not only increases in the rounds that directly follow the actual $\mathrm{R} \& \mathrm{D}$ contracting decision, but also remains at the higher level until the end of each five-rounds cycle. This holds until the end of the experiment, suggesting that the increase in degree of price collusion elicited by successful R\&D contracting is sustainable.

\subsection{R\&D decisions}

From the previous section we know that the degree of price collusion mostly lies somewhere between 0 and 1 . This implies that prices are predominantly

\footnotetext{
${ }^{18}$ When looking at $\beta=0$ and $\beta=1$ separately, the differences remain significant at a $2 \%$ level for all subsets of rounds provided that there are enough data that underlie the tests.
} 


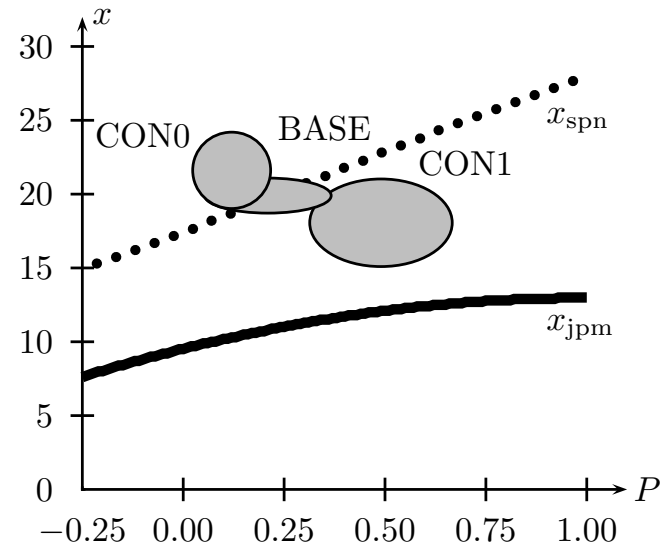

(a) $\beta=0$

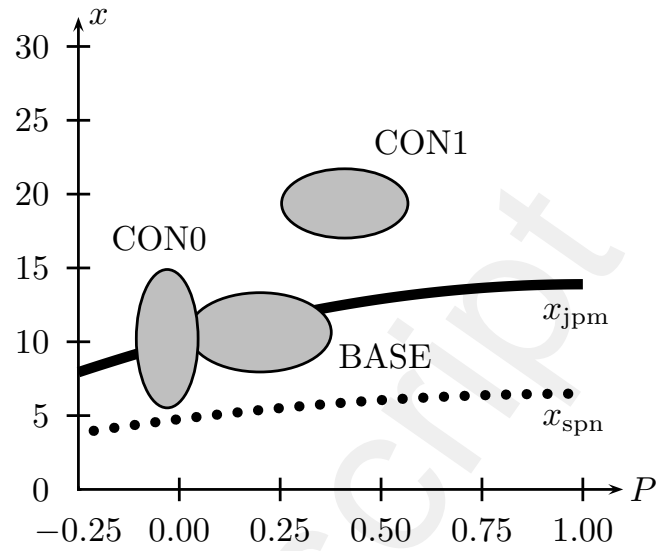

(b) $\beta=1$

Figure 2: R\&D decisions and benchmarks as a function of average degree of price collusion

not at the SPN or cooperative level. As a consequence, $R \& D$ decisions cannot simply be compared to the theoretical benchmarks given in table 1 that are based on the assumption of individual or joint profit maximizing behavior in the price-setting stages. Defining theoretical SPN and JPM R\&D decisions in terms of the degree of price collusion would allow us to compare the experimental $R \& D$ decisions with the $R \& D$ benchmarks corresponding to the price-setting behavior observed in the experiment. This can be done by using the coefficient of cooperation approach in the price-setting stage (see appendix B).

The coefficient of cooperation approach defines firm $i$ 's profit maximiza-

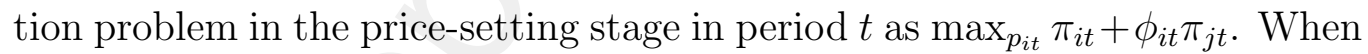
symmetry is assumed such that $\phi_{t}=\phi_{i t}=\phi_{j t}$ in period $t$, the SPN and JPM R\&D benchmarks can be defined in terms of $\phi_{t}$. Under symmetry, since a positive relation exists between the degree of price collusion, $P_{t}$, and $\phi_{t}$ (see also appendix B), the SPN and JPM R\&D benchmarks can be expressed in terms of the degree of price collusion. In figure 2 the dashed and bold lines represent the SPN and JPM R\&D benchmarks, respectively.

Figure 2 also contains ellipses, the centers of which represent average $\mathrm{R} \& \mathrm{D}$ decisions as a function of the average degree of price collusion for BASE, CON0 and CON1. The horizontal diagonals of the ellipses represent confidence intervals of the average degree of price collusion and the vertical diagonals represent confidence intervals of average R\&D decisions. Confidence intervals are calculated as the mean \pm 2 standard errors. 
The location of $\mathrm{R} \& \mathrm{D}$ decisions for $\beta=0$ in figure 2 suggests that $\mathrm{R} \& \mathrm{D}$ decisions in BASE and CON0 are close to the SPN prediction. In CON1 average $R \& D$ is below the line representing the SPN R\&D level, which is in the 'right' direction, given that cooperative $R \& D$ is smaller than SPN R\&D.

With $\beta=1$, the R\&D ellipses representing BASE and CON0 are located close to the curve representing $R \& D$ cooperation. Contracted $R \& D$ decisions (CON1) overshoot the cooperative level. Thus, with $\beta=1 \mathrm{R} \& \mathrm{D}$ decisions differ in the 'right' way between CON1 and BASE or CON0, although they are generally 'too high'. It could be the case that, with $\beta=1$, the $R \& D$ contracts have been used to signal a willingness to collude in prices. Indeed, since then $R \& D$ and price decisions both have positive externalities, joint profit maximization yields higher $\mathrm{R} \& \mathrm{D}$ and price decisions compared to their respective SPN equilibria. This form of signaling may have been more difficult and costly with $\beta=0$ because then R\&D decisions have negative externalities. In this case joint profit maximizing R\&D is lower than the SPN R\&D level. The finding that significantly more $R \& D$ contracts have been proposed and chosen with $\beta=1$ than with $\beta=0$ (Mann-Whitney- $\mathrm{U}$ tests give $p$-values of 0.017 and 0.049 , respectively) is in line with this suggestion ${ }^{19}$.

\section{A random-matching treatment}

In order to examine possible interaction between the finding that R\&D contracts facilitate price collusion and the matching scheme, we ran an additional random-matching treatment with $\mathrm{R} \& \mathrm{D}$ contract possibilities for the case of $\beta=1$ (henceforth referred to as RANCON, $\beta=1$ ). In RANCON, $\beta=1$ the counterpart of participants changed every five rounds and participants were informed about this in the instructions. For the rest, the same procedure as in the fixed-matching treatments has been followed.

RANCON, $\beta=1$ covered two sessions with 18 and 12 participants in each, respectively, giving 30 participants (15 duopolies) in total. The random matching was executed within groups of six participants, such that the first and the second session respectively produced 3 and 2 independent observations ( 5 in total). In what follows in this section, we present a short description of behavior in this treatment taking into account the same data considerations as in section 4.1.

Following expectations, the average degree of price collusion with random matching is lower than the one with fixed matching (see also Holt 1985, Huck et al. 2001). This is clearly shown in figure 3(a), which depicts the

\footnotetext{
${ }^{19}$ In chapter 10 of Suetens $(2005 \mathrm{~b}$ ) experimental evidence is provided that tends to confirm the suggestion.
} 


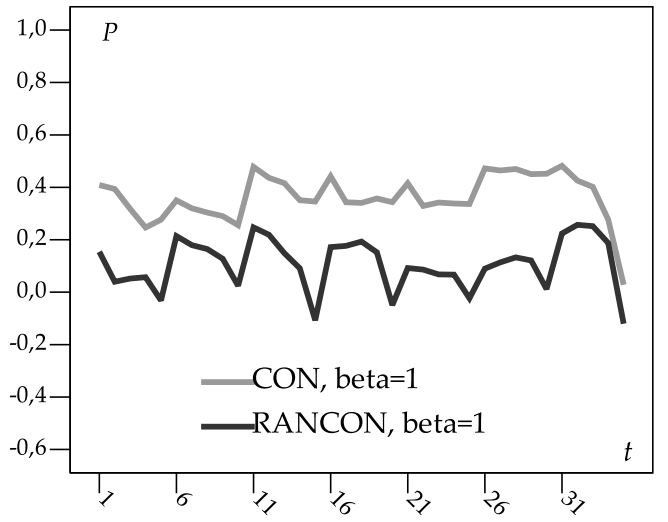

(a) $\mathrm{CON}$ and RANCON, $\beta=1$

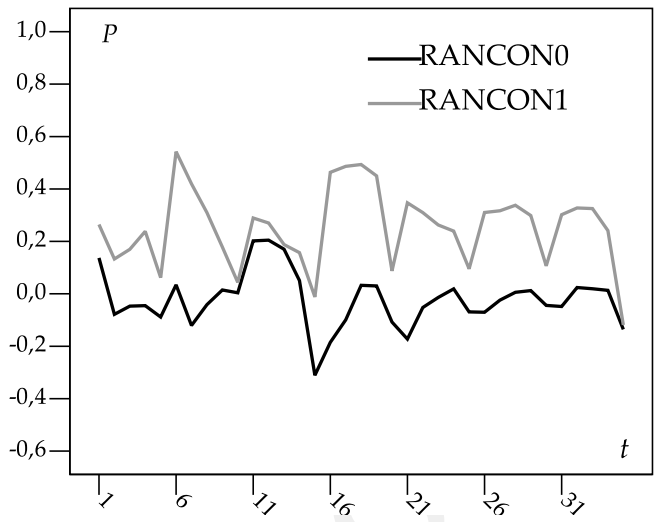

(b) within RANCON, $\beta=1$

Figure 3: Evolution of average degree of price collusion in RANCON, $\beta=1$

evolution of the average degree of price collusion in RANCON, $\beta=1$ and CON, $\beta=1^{20}$. A Mann-Whitney-U test based on independent observations provides evidence that, overall, the degree of price collusion is significantly lower with random matching than with fixed matching at the $10 \%$ level, with a two-tailed p-value of 0.066 .

Figure 3(b) further splits up RANCON, $\beta=1$ in RANCON0 and RANCON1, respectively based on rounds without and with R\&D contracts. Clearly, with random matching, the average degree of price collusion is higher when contracts are actually committed to than when not committed to ${ }^{21}$. It is thus unlikely that there is an interaction between the finding that $\mathrm{R} \& \mathrm{D}$ cooperation facilitates price collusions and the matching design.

With respect to the experimental $\mathrm{R} \& \mathrm{D}$ decisions in $\mathrm{RANCON}, \beta=1$, we find very similar patterns to $\mathrm{CON}, \beta=1$. Here also, $\mathrm{R} \& \mathrm{D}$ decisions are overall 'too high' compared to the theoretical benchmarks and there is considerable overshooting of contracted R\&D (see appendix C).

\section{Conclusion}

In this paper we examined whether $R \& D$ cooperation facilitates price collusion in experimental duopoly markets. Subjects in the experiment were asked

\footnotetext{
${ }^{20}$ We use CON, $\beta=1$ as a basis for comparison because RANCON, $\beta=1$ has contract possibilities and $\beta=1$. See appendix $\mathrm{C}$ for the average degree of price collusion and standard deviations in RANCON, $\beta=1$.

${ }^{21}$ For all subsets of rounds the Wilcoxon-signed ranks test gives two-tailed p-values of 0.063 , which is the best possible p-value for 5 independent observations.
} 
to make $R \& D$ and price decisions repeatedly. For two scenarios of technological spillovers (i.e. no spillovers $(\beta=0)$ and complete spillovers $(\beta=1)$ ), a treatment without binding $R \& D$ contracts and a treatment with binding contracts were run. An additional random-matching treatment with R\&D contracts has been run for $\beta=1$ in order to control for possible interaction effects between the matching design and the effectiveness of $R \& D$ contracts in facilitating price collusion.

We find strong support for the idea that binding R\&D cooperation facilitates price collusion. First, in the contract treatments significantly more price collusion is observed when $R \& D$ agreements are reached than in the baseline treatments. Second, within the contract treatments there is significantly more price collusion when $R \& D$ agreements are reached than when they are not.

This finding implies that econometric estimations of theoretical R\&D models based on field data that assume non-cooperative prices despite $\mathrm{R} \& \mathrm{D}$ cooperation would give seriously biased results. Moreover, for public authorities who have recently been lenient toward the formation of research joint ventures, the findings in the lab may provide a warning. Since the experimental setting is fully anonymous and excludes any possibility of personal contact or price signaling, the stimulating effect of successful R\&D agreements on price collusion may be viewed as a minimum effect. It is likely that in the field there exist many more opportunities for representatives of firms engaged in $R \& D$ cooperation to interact. However, cooperative R\&D agreements are often subsidized by governments, and information on the type of cooperation and the identity of participating firms is thus relatively easily available, providing an opportunity for public authorities to investigate the possibility of price collusion and fine colluding firms when necessary.

\section{Appendix A Translated instructions}

Note that the instructions are translated from the originals in Dutch and that additional instructions for the treatments with complete technological spillovers and the treatments with contract possibilities are in brackets and in bold.

You are participating in an economic experiment on decision-making of producers. During this session you will be asked to make a number of decisions. The amount of your earnings depends on your decisions and decisions of another participant. The instructions are simple. If you carefully follow them 
and make good decisions, the probability of earning more money is larger. During the experiment you are not allowed to communicate with other participants.

In the experiment, the economy is divided into a number of industries. In each of these industries two sellers-producers are active who sell and produce similar products. Each of you represents a seller-producer in a specific industry. The other producer in your industry (henceforth your counterpart) is in the same situation with the same conditions as you. Each producer, including you, has to take an investment decision first and then a price decision. The customers who eventually buy your products are simulated by the computer. The rule is: the higher the price of a certain variation of a product compared to another variation, the less products are bought of the first variation and the more of the other variation.

What you will earn, depends on your and your counterpart's investment and price decisions. Under the title 'Winstsimulatie' ['Profit simulation'] you always have the possibility to calculate your and your counterpart's profit. If you fill in hypothetical values of your own and your counterpart's investment, and of your own and your counterpart's prices, you can calculate your and your counterpart's hypothetical profit by clicking the button 'Bereken' ['Calculate']. By using this profit simulator you cannot input you final investment or price decision, it only serves as an aid with making your decisions.

Your investment decreases your [ and your counterpart's ] unit production cost (with the amount of the investment) on the one hand and presents a cost equal to half of the square [ the square ] of the amount of investment. Your final investment decision should be filled in under the title 'Finale investeringsbeslissing ingeven' ['Enter final investment decision']. Each time you made an investment decision, it will remain constant for 5 subsequent periods. You have 200 seconds to take each investment decision. The investment should be between 0,0 and 50,0.

[ In the investment stages you have the possibility to engage in a contract with your counterpart under the title called 'Contracten' ['Contracts']. You can send her/him a proposal to both invest a certain amount (fill in the proposal in the appropriate space and send it by clicking on 'Zend contractvoorstel' ['Send contract proposal']) and he/she can also send proposals. From the moment you sent a contract proposal, you are bound to invest what you proposed, if your counterpart has agreed with your proposal. Your own and your counterpart's proposals are shown on the screen. You can accept a proposal of your counterpart by selecting it and clicking on the button called 'Dit contract aanvaarden' ['Accept this contract']. If a contract is committed to, you (and your coun- 
terpart) are obliged to invest the contracted amount. You can find the number of the chosen contract on your screen. ]

When all investment decisions are made, a second screen shows up, where you again have the possibility to calculate your and your counterpart's profit on the basis of hypothetical decisions ['Winstsimulatie']. Information on your and your counterpart's investment decision in that period is given on your screen. In this second stage, you have to decide on the selling price of your products. Under 'Winstsimulatie' you can, e.g., fill in the investment decisions in that period, and hypothetical prices, so as to calculate the corresponding profit. Your final price decision should be given in under the title 'Finale prijsbeslissing ingeven' ['Enter final price decision']. You have 100 seconds take each price decision. The price should be between 0,0 and 245,0.

When all price decisions are made, a screen shows up with information on the decisions made in that period by you and your counterpart. Information on the profit earned in that period is also shown. You can continue by clicking on 'Ga door naar de volgende periode' ['Continue to the following period'].

As already mentioned, your investment decision remains constant during 5 subsequent periods. In the periods without investment decisions, only price decisions are to be taken. Information of the previous or the same period is always shown on the screen.

The experiment contains 40 periods which implies that eventually 8 investment and 40 price decisions will have been taken. The first 5 periods are practice periods and do not influence your final earnings. Your final earnings in Euro are calculated by dividing the total profit you made in the experiment (from period 6 to 40) by 1500. The experiment will take about 2 hours.

\section{Appendix B The coefficient of cooperation ap- proach}

Consider the following profit maximization problem, where a firm maximizes its own profit and a part $\phi_{i t}$ of the other firm's profit in period $t$ with $i=$ 1,$2 ; j=1,2 ; i \neq j$ :

$$
\max _{p_{i t}} \pi_{i t}+\phi_{i t} \pi_{j t}
$$

This approach is sometimes referred to as the coefficient of cooperation approach (see, e.g., Martin 2001). Solving this problem yields a price for $i$ expressed in terms of $x_{i 1}, x_{j 1}, \phi_{i t}$ and $\phi_{i t}$ :

$$
p_{i t}=p_{i t}\left(x_{i 1}, x_{j 1}, \phi_{i t}, \phi_{j t}\right) .
$$


$\phi_{i t}$ is clearly a measure for the cooperative preference of firm $i$ in period $t$. When $\phi_{i t}=0, p_{i t}$ is equal to equation 3 , which is the SPN price level that maximizes individual profit, and when $\phi_{i t}=1, p_{i t}$ is equal to equation 6 , which is the collusive price level that maximizes joint profit. For $0<\phi_{i t}<1$ it is clear that $p_{i t}$ lies between both benchmarks. The degree of price collusion representative for the duopoly can thus be measured by $\phi_{t}=\frac{\sum_{i=1,2} \phi_{i t}}{2}$ for $i=1,2 ; j=1,2$ and $i \neq j$.

We calculate the degree of price collusion of a duopoly in period $t$ as follows:

$$
P_{t}=\frac{\bar{p}_{t}-\bar{p}_{t}^{\mathrm{SPN}}}{\bar{p}_{t}^{\mathrm{SPM}}-\bar{p}_{t}^{\mathrm{SPN}}}
$$

where $\bar{p}_{t}=\frac{\sum_{i=1,2} p_{i t}}{2}$ and $\bar{p}_{t}^{\mathrm{K}}=\frac{\sum_{i=1,2} p_{i t}^{\mathrm{K}}}{2}$ with $\mathrm{K}$ representing SPN or JPM. As $P_{t}=0(1)$ the average price of the duopoly in period $t$ is at the SPN (JPM) level.

When $\mathrm{R} \& \mathrm{D}$ decisions and collusion preferences are symmetric such that $x_{i 1}=x_{j 1}$ and $\phi_{t}=\phi_{i t}=\phi_{j t}$ for $i=1,2 ; j=1,2 ; i \neq j$, we get the following relation between both measures of degree of price collusion in period $t$ by filling in (10) in (9) :

$$
P_{t}=\frac{2 \phi_{t}(b-c)}{2 b-c\left(\phi_{t}+1\right)},
$$

where for any value of $\phi_{t}$ between 0 and $1, P_{t}$ is increasing and convex in $\phi_{t}$.

\section{Appendix C Average decisions in RANCON,}

\begin{tabular}{|c|c|c|c|c|}
\hline & $\bar{P}_{1-35}$ & $\bar{P}_{26-35}$ & $\bar{P}_{1 s t}$ & $\bar{P}_{5 t h}$ \\
\hline RANCON0 & $-0.03(0.08)$ & $-0.02(0.06)$ & $-0.04(0.11)$ & $-0.09(0.08)$ \\
\hline RANCON1 & $0.20(0.12)$ & $0.25(0.10)$ & $0.30(0.14)$ & $-0.01(0.06)$ \\
\hline & $\bar{x}_{1-35}$ & $\bar{x}_{26-35}$ & & \\
\hline RANCON0 & $6.8(3.0)$ & $3.7(3.0)$ & & \\
\hline RANCON1 & $20.0(1.3)$ & $18.8(2.4)$ & & \\
\hline
\end{tabular}
$\beta=1$

\section{References}

Amir, R., 2000. Modelling imperfectly appropriable R\&D via spillovers. Journal of Industrial Organization 18, 1013-32. 
Belderbos, R., Carree, M., Diederen, B., Lokshin, B., Veugelers, R., 2004. Heterogeneity in $R \& D$ cooperation strategies. International Journal of Industrial Organization 22, 1237-63.

Brod, A., Shivakumar, R., 1997. R\&D cooperation and the joint exploitation of R\&D. Canadian Journal of Economics 30, 672-84.

Cabral, L., 2000. R\&D cooperation and product market competition. International Journal of Industrial Organization 18, 1033-47.

Cason, T., 1994. The impact of information sharing opportunities on market outcomes: an experimental study. Southern Economic Journal 61, 18-39.

Cason, T., 1995. Cheap talk price signaling in laboratory markets. Information Economics and Policy 7, 183-204.

Cason, T. N., Mason, C. F., 1999. Information sharing and tacit collusion in laboratory duopoly markets. Economic Inquiry 37, 258-81.

Cassiman, B., Veugelers, R., 2002. R\&D cooperation and spillovers: some empirical evidence from Belgium. American Economic Review 92, 116984.

d'Aspremont, C., Jacquemin, A., 1988. Cooperative and noncooperative R\&D in duopoly with spillovers. American Economic Review 78, 11337.

Davis, D., Holt, C., 1993. Experimental economics. Princeton University press, New Jersey.

Fehr, E., Rockenbach, B., 2003. Detrimental effects of sanctions on human altruism. Nature 422, 137-40.

Fischbacher, U., 1999. Z-tree: A toolbox for readymade economic experiments. Working Paper 21, University of Zurich.

Harstad, R., Martin, S., Normann, H., 1998. Experimental tests of consciously parallel behaviour in oligopoly. In: Phlips, L. (Ed.), Applied Industrial Organization. Cambridge University Press, Cambridge.

Henriques, I., 1990. Cooperative and noncooperative R\&D in duopoly with spillovers: comment. American Economic Review 80, 638-40.

Hernán, R., Marín, P., Siotis, G., 2003. An empirical evaluation of the determinants of research joint venture formation. Journal of Industrial Economics 51, 75-89. 
Hinloopen, J., 2003. R\&D efficiency gains due to cooperation. Journal of Economics 80, 107-25.

Holt, C., 1985. An experimental test of the consistent-conjectures hypothesis. American Economic Review 75, 314-25.

Holt, C., 1995. Industrial organization: a survey of laboratory research. In: Kagel, J., Roth, A. (Eds.), The handbook of experimental economics. Princeton University Press, New Jersey, pp. 349-444.

Holt, C., Davis, D., 1990. The effects of non-binding price announcements on posted-offer markets. Economics Letters 34, 307-10.

Huck, S., Normann, H., Oechssler, J., 2001. Market volatility and inequality in earnings: experimental evidence. Economics Letters 70, 363-68.

Huck, S., Normann, H., Oechssler, J., 2004. Two are few and four are many: number effects in experimental oligopolies. Journal of Economic Behavior and Organization 53, 435-46.

Isaac, R., Reynolds, S., 1992. Schumpeterian competition in experimental markets. Journal of Economic Behavior and Organization 17, 59-100.

Jullien, C., Ruffieux, B., 2001. Innovation, avantages concurrentiels et concurrence. Revue d'Économie Politique 111, 121-50.

Kaiser, U., 2002. An empirical test of models explaining research expenditures and research cooperation: evidence for the German service sector. International Journal of Industrial Organization 20, 747-74.

Kamien, M., Muller, E., Zang, I., 1992. Research joint ventures and R\&D cartels. American Economic Review 82, 1293-306.

Keser, C., 2000. Cooperation in symmetric duopolies with demand inertia. International Journal of Industrial Organization 18, 23-38.

Lambertini, L., Poddar, S., Sasaki, D., 2002. Research joint ventures, product differentiation and price collusion. International Journal of Industrial Organization 20, 829-54.

Martin, S., 1995. R\&D joint ventures and tacit product market collusion. European Journal of Political Economy 11, 733-41.

Martin, S., 2001. Advanced Industrial Economics. Blackwell Publishers, Cambridge. 
Petit, M., Tolwinski, B., 1999. R\&D cooperation or competition? European Economic Review 43, 185-208.

Salant, S., Shaffer, G., 1998. Optimal symmetric strategies in research joint ventures. International Journal of Industrial Organization 16, 195-208.

Selten, R., Stoecker, R., 1986. End behaviour in sequences of finite prisoner's dilemma supergames. Journal of Economic Behavior and Organization 3, $47-70$.

Suetens, S., 2005a. Cooperative and noncooperative R\&D in experimental duopoly markets. International Journal of Industrial Organization 23, 6382.

Suetens, S., 2005b. R\&D cooperation and strategic decision-making in oligopoly: an experimental economics approach. Ph.D. thesis, University of Antwerp.

Suzumura, K., 1992. Cooperative and noncooperative R\&D in an oligopoly with spillovers. American Economic Review 82, 1307-20.

Tirole, J., 1995. The Theory of Industrial Organization. The MIT Press, Cambridge.

van Wegberg, M., 1995. Can R\&D alliances facilitate the formation of a cartel? The example of the European IT industry. Research Memorandum 004, Maastricht University, METEOR.

Vonortas, N., 2000. Multimarket contact and inter-firm cooperation in R\&D. Journal of Evolutionary Economics 10, 243-71. 